\title{
Optical Line Monitoring System Using Optical Fiber Closure
}

\begin{abstract}
This paper examines an optical fiber closure and optical line monitoring system. Currently available optical fiber closures do not support centralized real-time control of their on/off status when opening business to business (B2B) and business to company (B2C) lines. This problem can be addressed by a range of methods such as real-time optical line monitoring, optical line failure alerts followed by immediate search of the failure location, an optical fiber closure open/closed state monitoring and alert system, and a periodic optical line status inspection system. This paper investigates a monitoring system in which a connector and a tray are installed inside an optical fiber closure to enable the operator to turn it off to block optical signals so that the central office can detect faults in real time through an optical time-domain reflectometer (OTDR) and issue an alert. This study is expected to contribute to network quality stabilization by enabling a rapid and efficient optical line management.
\end{abstract}

So-Ki Jung
Keywords-Optical Fiber Closure, Monitoring System, Signal block, Connector or Tray, OTDR.

\section{I.INTRODUCTION}

Optical communication is a communication medium for long distance transmission of a large amount of data using light (laser) in optical glass fibers. Driven by the rapid increase in the subscriber base owing to the advent of ultrafast Internet service in the early 2000s, the information and communication network infrastructure emerged as a national agenda in Korea. With the government and telecom companies (hereafter "telcos") stepping up their investment and R\&D in this field ever since, optical communication in Korea has experienced its long-lasting heyday. Each year has seen rapid expansion in optical communication media[1]. In particular, due to the recent exponential increase in Internet penetration, hundreds of gigabits of data are transmitted per channel every second. Alongside this steep growth in Internet connectivity, optical line failure and its ripple effects are posing a variety of problems[1]. Efficient network maintenance and repair is a great challenge because the risk factors for most optical line failure events are external, such as online outputs of an unspecified number of network participants, bending, road construction, waterworks, and utility pole relocation.

Revised Manuscript Received on July 05, 2019. So-Ki Jung, SKbroadband Seoul City, Republic of Korea.
In particular, defective optical cables and fiber closures are causes of economic losses to both network operators (repair costs) and customers (e.g., stock exchange and banking transactions)[2]. Telcos are therefore developing optical line fault detection and testing systems to minimize optical cable failure through optimal maintenance, quality measurement, and failure minimization[3]. With ever-expanding business to business (B2B) and business to company (B2C) commercial transactions, telcos have been expanding their services by installing new access lines, mostly using existing cable links, such as optical fiber closures. Negligent handling of optical fiber closures often results in optical core bending or failure of the existing cable connection. However, such defects are not immediately noticeable for lack of electrical signals within an optical fiber closure. For this reason, anybody can arbitrarily open an optical fiber closure without being detected. In other words, optical fiber closures are vulnerable to unauthorized manipulation because they lack locking devices such as a tray or adapter linked to the central office which would enable their remote monitoring. Location identification is also a great challenge for the central office without access to real-time spatial data via GIS, ${ }^{1}$ NMS, 2 or optical time-domain reflectometry (OTDR). ${ }^{3}$ For example, if an unauthorized person opens an optical fiber closure to destroy it, the central office has no way to detect it until the optical cable within it has been cut, and a considerable length of time is required to revive the connection. Nor is there any means to immediately alert the technician when the optical fiber closure is sealed after cable branching to install a new connection, but with the existing lines left unconnected[4].

This paper presents a system designed to send an alarm to an NMS when an optical fiber closure ${ }^{4}$ is opened or closed, detect optical line faults or changes in real time, and identify faulty locations through linkage to OTDR, GIS, and administrative maps. It also proposes a method of rapid and efficient optical line operation by periodically

1 GIS (Geographic Information System): a system that analyzes and processes geospatial data and applies the results to relevant fields such as traffic and telecommunications [5].

2 NMS (Network Management System): a system used by telecommunication companies for network maintenance and repair[6].

3 OTDR (Optical Time Domain Reflectometry): a device that measures fiber backscattering to determine splice loss and connector loss[5].

4 Optical Fiber Closure: an encasement for accomnodating and protecting spliced optical cables[fึ]. 


\section{OPTICAL LINE MONITORING SYSTEM USING OPTICAL FIBER CLOSURE}

measuring and analyzing its status. Furthermore, to ensure reliability and enhance service quality, it provides data for statistical analysis stored in a server database containing defect characteristics of different optical line segments, drawing on earlier measurements[6-9,10-13,15]. Field testing was carried out by applying the proposed monitoring system and dark fiber to a monitoring system of S Telco and 11 existing optical fiber closures. Testing was performed in compliance with the pertinent ITU-T recommendations and specifications of the authors' invention. The rest of this paper is organized as follows: Section II gives an overview of an optical fiber closure, defines the proposed monitoring system, and explains the operating principles of the optical fiber closure monitoring system and its components; Section III describes the details of the experimental tests of the performance of the optical fiber closure opening/closing monitoring system in field settings and its interoperability with an NMS; Section IV draws conclusions and presents future research directions.

\section{Operating principles of the optical fiber closure monitoring system and its components}

An optical fiber closure is an encasement that stores and protects optical fibers which are spliced together[7]. Telcos install optic cables in three separate network segments: feeder, distribution, and drop networks. B2B and B2C channels are laid at intervals of 1 kilometer in general, and at shorter intervals in populated areas, where optical cables consist of only feeder and drop networks [7]. End-to-end optical signal connections are made through pre-terminated cables, using wavelengths with a laser as the signal source, from a telco's large-capacity router and concentration switch to the feeder network passing through fiber distribution frames (FDFs) and to the drop network passing through optical fiber closures. Of in-out and butt-type closures, Raychem supplies only domeshaped butt-type closures. This closure is very useful for in situ splicing-since it is connected externally using the clamping method, there is no need to use other tools for opening and closing. Optic fibers are spliced by the differential thermal contraction between the two fibers. Both fusion splicing and mechanical splicing can be used for core alignment. High-density polyethylene is used as outer material, which can resist cracking or breaking in harsh environments[7].

Fig. 1 shows that the optical line monitoring system covers the backhaul network, feeder ring network, and optical network terminals in the subscriber's premises in single- and multi-family dwellings. The feeder ring network is composed of several access nodes and can be referred to collectively as the downstream feeder network. In this network segment, at least one optical fiber closure can be installed among the access nodes. A closure performs the functions of straight or mid-span splicing or branching of the optical cable, and can be mounted in buried or aerial settings[7]. Inside the closure, several

splices can be prepared, to each of which a cable core can be fixed. While carrying out these tasks, the closure remains open. When the sealing cover is opened, cable core bending can occur, and the resulting bending loss can be detected in the central office, if the closure is thus configured[14].

To ensure rapid and efficient optical line operation, the optical line monitoring system is designed to carry out the following tasks: monitoring the optical line in real-time, alarming in the event of optical line failure and immediately locating the event, sending closure opening/closing alarms, and periodically measuring and analyzing fiber loss changes. In Fig. 1, the telco's central control system $(\mathrm{CCS})^{5}$ is connected with the core or metro network, where it distributes the optical signals and sends them to the drop network. The feeder network is monitored in this process. When the sealing cover is opened, optical loss or signal loss caused by connector separation is also detected. The CCS issues an alarm on detecting feeder network failure or an abnormal open state of the closure. The CCS, FDF, and OTDR can be equipped with a switch for that purpose.

Specifically, a CCS access router $^{6}$ is installed at a location with the minimum downstream traffic. An FDF is a housing that receives and distributes branched optical lines from a core network or a metro network to an optical distribution network[4]. The OTDR can detect a faulty location by injecting a series of optical pulses with wavelengths different from those of the signal lights into the optical line of the feeder network and analyzing the distance distribution of the amount of light reflected from each reflecting point along the optical line, thus measuring the optical fiber loss, the distance to the connector, splice loss, and the number of reflected signals from the connector. Furthermore, the OTDR can trace the location of the optical fiber closure at the instant of its opening[5].

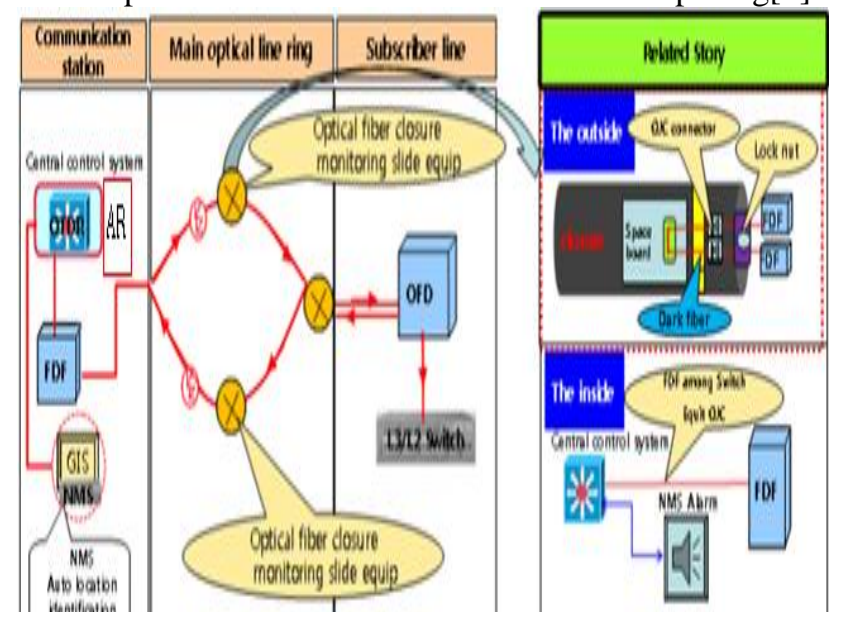

\footnotetext{
${ }^{5}$ CCS (Central Control System): a central control unit that monitors the telecommunication network including optical cable and equipment disturbances [4]. and Engi

${ }^{6}$ AR (Access Router): a large-capacidy act angin'poutter installed according to amount of downstr

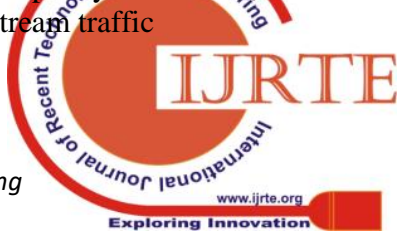




\section{OPTICAL LINE MONITORING SYSTEM USING OPTICAL FIBER CLOSURE}

Fig. 1. A functional block diagram of the optical fiber closure monitoring system.

Table 1: presents the components of the dome-type optical fiber closure (hereafter the "dome closure") illustrated in Fig. 2 and Fig. 3.

\begin{tabular}{|c|c|c|c|}
\hline No & Contents & No & Contents \\
\hline 200 & closure & 280,720 & Sealing cover \\
\hline 212,214 & $\begin{array}{c}\text { Optical cable } \\
\text { Directories }\end{array}$ & 290,760 & $\begin{array}{c}\text { The second } \\
\text { Connector } \\
\text { fixture }\end{array}$ \\
\hline 220 & Main holder & 330,730 & The first fixture \\
\hline 230 & Splice & 810 & $\begin{array}{c}\text { Inside optical } \\
\text { cable }\end{array}$ \\
\hline 240 & $\begin{array}{c}\text { Inside optical } \\
\text { fiber }\end{array}$ & 820 & $\begin{array}{c}\text { Outside optical } \\
\text { cable }\end{array}$ \\
\hline 250 & \multicolumn{2}{|c|}{ Space board fixture } & \\
\hline 260,270 & \multicolumn{3}{|c|}{ The third/fourth connector } \\
770,780
\end{tabular}

The dome closure is composed of a cable guide unit, main holder, splice tray, sealing cover, and connector. The cable guide unit connects each incoming cable with the main holder; it is designed to prevent the infiltration of foreign bodies into the housing. The first fixture for fixing two connectors is structured to allow one-touch insertion of two connectors, which are mounted on the cable guide unit with bolts and two square holders. The first fixture is configured to fix two connectors and be loaded on the main holder simultaneously. The main holder is attached to the cable guide unit to fix and support it so that several splice trays can be stably stacked on it. To this end, the main holder was configured to hold the connectors and splice trays. The connectors are arrayed to protrude from the fixture[4]. The splice holder, which aligns cable cores, is placed on the side opposite to the connector side. It has a plurality of thru-holes for fixing and storing active and unused cable cores, and it also fastens the sleeves after splicing. In the example shown in Fig. 2, the first fixture was placed on the cable guide unit; however, it can be placed on the main holder as well. The first fixture is then aligned on the same line connecting the main holder connection part and the splice tray fixture[4]. The square optical fiber closure in Fig. 3 consists of a sealing cover, splice trays, cable guide unit, connectors. The cable guide unit and sealing cover are hinge-connected. A hinged connection allows free rotation of the cover. The cable guide unit and sealing cover are hermetically sealed together. The cable guide unit accommodates inlet and outlet ports for cables. Inside the cable guide unit, there is a space and latches for fastening the splice trays, where active and unused cable cores are embedded for splicing or termination. The splice trays in Figure 3A are securely fastened inside the housing. This rectangular closure allows two incoming connectors to be connected to the end of the cable core of either of the outgoing cables. The third connector in Fig. 3A is connected to one end of the optical fiber laid on the splice tray, and the fourth connector to the other end.

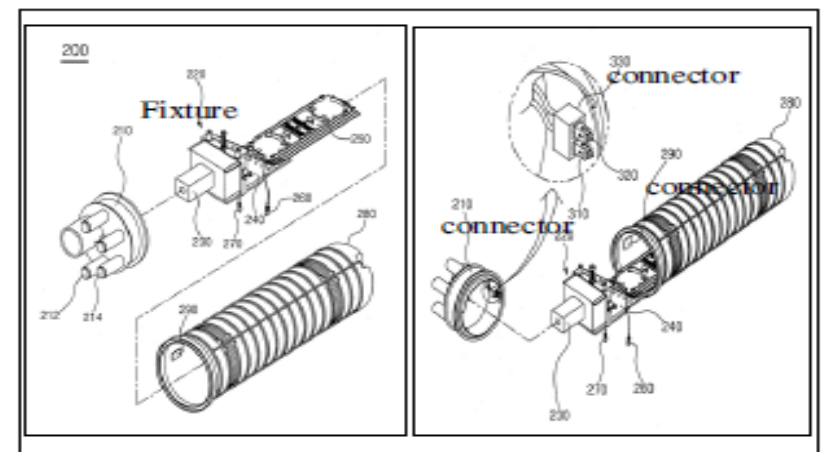

Fig. 2. Drawings of the components of the connector of a dome closure[4].
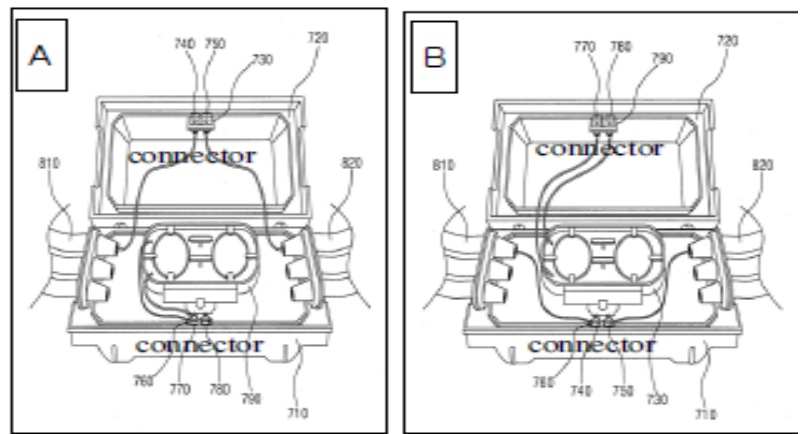

Fig. 3. Drawings of the components of the connector of a square closure[4].

The first and second fixtures are formed on the cable guide unit or the sealing cover, and connectors $730,740,750$ are inserted and fixed. When the sealed closure is opened, the connectors are separated, blocking optical signals, and the alarm goes off in the central control system[4]. As explained above, connectors are installed and interlocked within an optical fiber closure and its separation sends an alarm to the CCS.

Table 2 lists the components of the optical fiber closure monitoring system, as illustrated in Fig. 4. The optical fiber closure is designed to accommodate the following components: cable guide unit, splice tray, main holder, sealing cover, connector fixture, stopper, slide member, nut, and protrusion.

Table 2: Components of the optical fiber closure monitoring system[14].

\begin{tabular}{|c|c|c|c|}
\hline NO & Contents & NO & Contents \\
\hline 200 & Closure & 255 & 1,2 connector \\
& 260 & \\
\hline 210 & Optical Directories & 290 & Connector fixture \\
\hline 220 & Sealing cover & 300 & Stopper \\
\hline 230 & Main holder & 310 & Slide member \\
\hline 235 & Splice & 321 & Protrusion \\
\hline 238 & Space board fixture & 323 & Through hole \\
\hline 240 & Inside/outside & 325 & A nut \\
241 & optical fiber & & \\
\hline 250 & Optical fiber & & \\
\hline
\end{tabular}




\section{OPTICAL LINE MONITORING SYSTEM USING OPTICAL FIBER CLOSURE}

One end of the stopper is fixed to the inner surface of the sealing cover and the other end is left detachable. One end of the slide member which moves along the sliding guide is fixed and the other end is left to be attachable or detachable to an attach/detach unit implemented for this purpose. At both ends of the slide guide, there are fixing hooks that prevent the slide member from moving beyond the distance limit. One end of the slide member moves along the slide guide and the other end is either attached to or detached from the attach/detach unit. This is implemented through a hole made through the attach/ detach end of the slide member as well as the corresponding protrusion and nut. As shown in Fig. 4, a screw thread is formed on the protrusion (4), and a nut is used along the screw thread to fasten the slide member. The movement of the slide member is restricted at both ends by the main holder and the cable guide unit, respectively. Stopper 3 can also be equipped with a fixing hook to provide both ends of the slide member with the attach/detach function. Additionally, the length of this stopper prevents excessive pulling of the cable core exiting from the splice tray when the sealed cover is opened, thus preventing fiber failure. The protrusion of the attach/detach unit is wedge-shaped, which allows fastening without a nut. The degree of protrusion can be lower than that illustrated in Fig. 4 if deviation prevention can be provided at both ends of the rail. The exiting optical line would break if the slide member moves to the maximum possible displacement. To prevent this, the technician in charge should first deal with the connectors at the first and third connector fixtures[14]. Through the sealing or separation status, the CCS can detect the open or closed status of the optical fiber closure in real time.
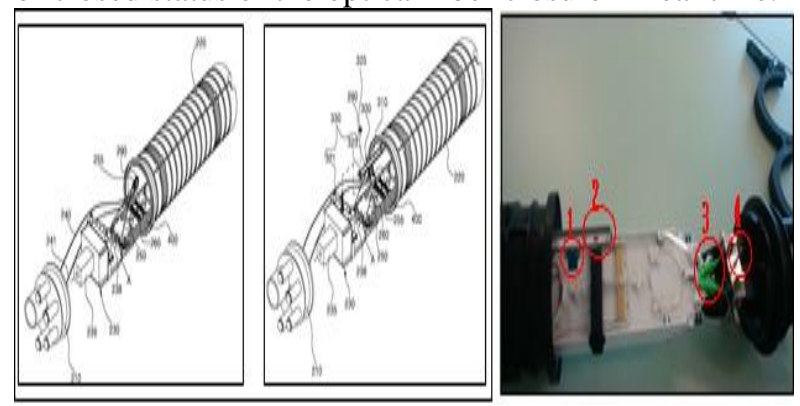

Fig. 4. Drawings and snapshot of the components of the sliding members of the dome optical fiber closure[14].

Table 3 lists the components of the slide member as illustrated in Figure 5: fixture unit, connector holding unit, and slide fixture bracket unit. If a slide is mounted using the components of these units and is attached to the optical fiber closure cover, the closure is transformed into a monitoring apparatus. It provides a lock function when the closure is opened or closed and it implements a connector that can be monitored by the CCS. The slide itself can be deformed depending on the size of the optical fiber closure cover. The inner surface of the closure cover is equipped with a serrated fastener.

Table 3: Components of the slide member mounted inside the optical fiber closure.

\begin{tabular}{|c|c|c|c|c|c|}
\hline $\mathrm{NO}$ & Contents & $\begin{array}{c}\text { Quan } \\
\text { tity }\end{array}$ & NO & Contents & $\begin{array}{l}\text { Quan } \\
\text { tity }\end{array}$ \\
\hline 1 & Slide Rail & 1 & 4 & $\begin{array}{l}\text { A Connector } \\
\text { holder }\end{array}$ & 1 \\
\hline 2 & $\begin{array}{l}\text { Slide fixed } \\
\text { Bracket(A) }\end{array}$ & 2 & $4-1$ & $\begin{array}{l}\text { A Connector } \\
\text { holder assembly a } \\
\text { bolt }\end{array}$ & 2 \\
\hline $2-1$ & $\begin{array}{c}\text { Slide fixed } \\
\text { Bracket(A) } \\
\text { assembly a bolt }\end{array}$ & 4 & $4-2$ & $\begin{array}{c}\text { A Connector } \\
\text { holder assembly a } \\
\text { nut }\end{array}$ & 2 \\
\hline $2-2$ & $\begin{array}{c}\text { Slide fixed } \\
\text { Bracket(A) } \\
\text { assembly a nut }\end{array}$ & 4 & 5 & Connector & 1 \\
\hline 3 & $\begin{array}{l}\text { Slide fixed } \\
\text { Bracket(B) }\end{array}$ & 1 & $5-1$ & $\begin{array}{c}\text { Connector assembly } \\
\text { a bolt }\end{array}$ & 2 \\
\hline $3-1$ & $\begin{array}{c}\text { Slide fixed } \\
\text { Bracket(B) } \\
\text { assembly a bolt }\end{array}$ & 3 & 6 & $\begin{array}{c}\text { Optical } \\
\text { Jumper Cord }\end{array}$ & 2 \\
\hline $3-2$ & $\begin{array}{c}\text { Slide fixed } \\
\text { Bracket(B) } \\
\text { assembly a nut }\end{array}$ & 3 & & & \\
\hline
\end{tabular}

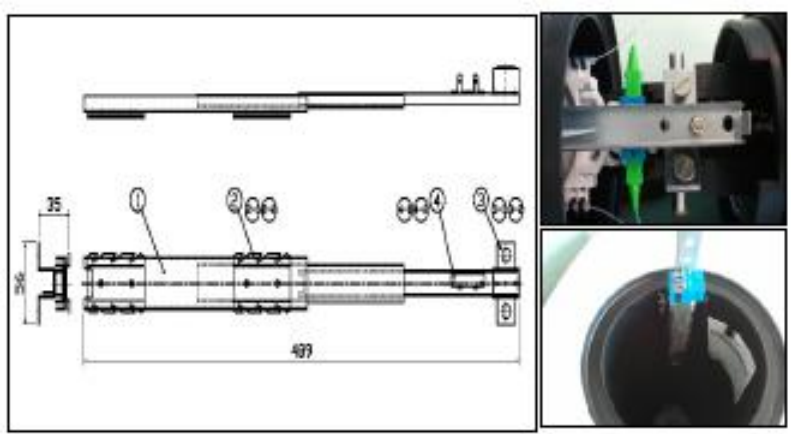

Fig. 5. Optical fiber closure inside of equip Slide a plane figure

In the following, we will examine the structure and operating principles of the optical line monitoring system. A monitoring system should have economically feasible and efficient structure and function, as well as easy in situ application. Also, its operation should not affect other systems and the optical line and its operation status should be easily checked through a visual sign, for example, an LED light linked to each module. Most importantly, communication and power cables should have an architecture that allows easy assembly and dismantling[3$4,10-13,15]$. Table 4 gives an overview of the configuration of the optical line monitoring system.

The operating capacity of the proposed optical line monitoring system can be extended by the channel unit, up to 64 channels[6,10,11,13,15,16]. Each module has a plug-in unit-mounting structure that can insulate the backside of the module or prevent the module from slipping from the slot, thus preventing contact loss and short-circuits between units during mounting and dismounting. The optical supervisory channel accommodates the channel card 8EA with a common extended shelf, and the channel card accommodates four supervisory channels.

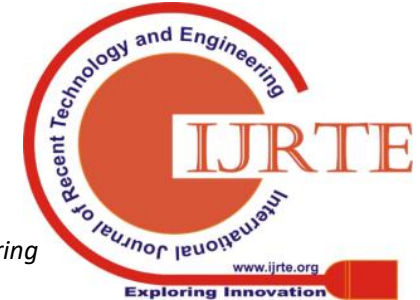




\section{OPTICAL LINE MONITORING SYSTEM USING OPTICAL FIBER CLOSURE}

Table 4: Operation modules of the optical line monitoring system[6].

\begin{tabular}{|c|c|c|}
\hline \multirow{4}{*}{$\begin{array}{c}\text { Commo } \\
\text { n } \\
\text { Part }\end{array}$} & $\begin{array}{l}\text { Main } \\
\text { control } \\
\text { unit }\end{array}$ & Each module monitoring or control \\
\hline & $\begin{array}{l}\text { Power } \\
\text { supply }\end{array}$ & $\begin{array}{l}\text { Power supply Duplex configuration in } \\
\text { monitoring system }\end{array}$ \\
\hline & $\begin{array}{l}\text { OTDR } \\
\text { Measurem } \\
\text { ent }\end{array}$ & $\begin{array}{c}\text { Abnormal state monitoring of periodic } \\
\text { loss change, } \\
\text { Optical fiber cable of cut location } \\
\text { exploration }\end{array}$ \\
\hline & $\begin{array}{l}\text { Optical } \\
\text { fiber } \\
\text { Select }\end{array}$ & $\begin{array}{l}\text { The majority optical core wire among } \\
\text { measured optical core wire select it }\end{array}$ \\
\hline \multicolumn{2}{|c|}{$\begin{array}{l}\text { Optical monitoring } \\
\text { Channel }\end{array}$} & $\begin{array}{l}\text { Real time with optical fiber cable } \\
\text { measure of length, delay measure }\end{array}$ \\
\hline \multicolumn{2}{|c|}{$\begin{array}{ll}\text { Optical cable } \\
\text { Space equip }\end{array}$} & $\begin{array}{l}\text { Space equip component arrange of } \\
\text { optical cable }\end{array}$ \\
\hline
\end{tabular}

In the optical line selection unit, the main switch module of $1: 8$ is selected as the basic mounting, and the extension switch module is mounted when 1:8 is exceeded. Table 5 presents the details of the system performance in three assessment areas: OTDR measure, optical supervisory channel, and optical light select. Processing of connector loss, faulty location identification, and segmentwise or total loss and the like pertain to the OTDR function[6].

Table 5: Optical line monitoring system evaluation items[6].

\begin{tabular}{|c|c|c|c|}
\hline \multicolumn{4}{|c|}{ OTDR Measure } \\
\hline \multicolumn{2}{|c|}{ Optical connector } & & $\mathrm{FC} / \mathrm{PC}$ \\
\hline \multicolumn{2}{|c|}{ Fiber Type } & & Single-mode \\
\hline \multicolumn{2}{|c|}{ Insertion Loss } & & $0.5 \mathrm{~dB}$ Below \\
\hline \multicolumn{2}{|c|}{ Dynamic Method } & & Back Scattering \\
\hline \multicolumn{2}{|c|}{ Dynamic Wave } & & $1310 \mathrm{~nm}, 1550 \mathrm{~nm}$ \\
\hline \multicolumn{2}{|c|}{ Dynamic Range } & & 35dB@1310/1550nm \\
\hline \multicolumn{2}{|c|}{ Light Source } & & d FP LD output 40Mw Over \\
\hline \multicolumn{2}{|c|}{ Event Dead Zone } & & 2m@ event, 10m@atten \\
\hline \multicolumn{2}{|c|}{ Sampling Resolution } & & $0.25 / 0.5 / 1 / 2$ meter \\
\hline \multicolumn{2}{|c|}{ Distance Accuracy } & & 5 meter below per $100 \mathrm{~km}$ \\
\hline \multicolumn{2}{|c|}{ Pusle } & & $10 \mathrm{~ns}, 30 \mathrm{~ns}, 100 \mathrm{~ns}, 300 \mathrm{~ns}$ \\
\hline \multicolumn{4}{|c|}{ Optical fiber select } \\
\hline \multicolumn{3}{|c|}{ Optical Connector } & $\begin{array}{c}\text { OTDR, Extension Switch; } \\
\text { LC/PC }\end{array}$ \\
\hline \multirow{6}{*}{$\begin{array}{l}\text { Main } \\
\text { Switch }\end{array}$} & \multicolumn{2}{|c|}{ Switching Capacity } & $1: 8$ \\
\hline & \multicolumn{2}{|c|}{ Insertion Loss } & $2 \mathrm{~dB}$ below (In<->Out) \\
\hline & \multicolumn{2}{|c|}{ Return Loss } & $50 \mathrm{~dB}$ over \\
\hline & \multicolumn{2}{|c|}{ Crosstalk } & $50 \mathrm{~dB}$ over \\
\hline & \multicolumn{2}{|c|}{ Switching Time } & $25 \mathrm{~ms}$ below \\
\hline & \multicolumn{2}{|c|}{$\begin{array}{c}\text { Reliability } \\
\text { Switching number }\end{array}$} & 10million over \\
\hline \multirow{2}{*}{$\begin{array}{l}\text { Extention } \\
\text { Switch }\end{array}$} & \multicolumn{2}{|c|}{ Optical Connector } & $\begin{array}{l}\text { OTDR, optical monitoring } \\
\text { channel : LC/PC }\end{array}$ \\
\hline & \multicolumn{2}{|c|}{ Switching Capacity } & $1: 8$ \\
\hline
\end{tabular}

where $\mathrm{L}$ is the fiber loss and $\mathrm{P} 1[\mathrm{~W}]$ and $\mathrm{P} 2[\mathrm{~W}]$ are the input and output optical power, respectively.

Optical power can be expressed by Eq. (3):[17]

$$
\text { ai }=-10 \log 10 \text { Pout/Pin }- \text { nLc }
$$

where Lc is the connector loss, $\mathrm{n}$ is the number of connector splicings between the dummy and measured fibers, Pin is the optical power after passing the connector connected with the light source of the entering end through the entering end of the connector pair's crosssection, Pout is the optical power after passing the connector of the measured fiber, and ai is the fiber loss. Splice loss can be calculated by measuring the reflectance from the faulty points such as connectors and splices with the backscatter from the fiber generated under different incident wavelengths.

\section{Experimental}

Fig. 6 shows the results of field testing Company S's prototype 


\section{OPTICAL LINE MONITORING SYSTEM USING OPTICAL FIBER CLOSURE}

implementing the proposed optical line monitoring system. In the experiments, the performance of the currently operating NMS and OTDR was tested in tracing the optical line failure caused by connector separation in an optical fiber closure. According to OTDR measurements, the fiber failure took place at the $4.14987 \mathrm{~km}$ point vs. $5.94143 \mathrm{~km}$ before the damage done under the scenario of connector separation during work on the optical fiber closure.
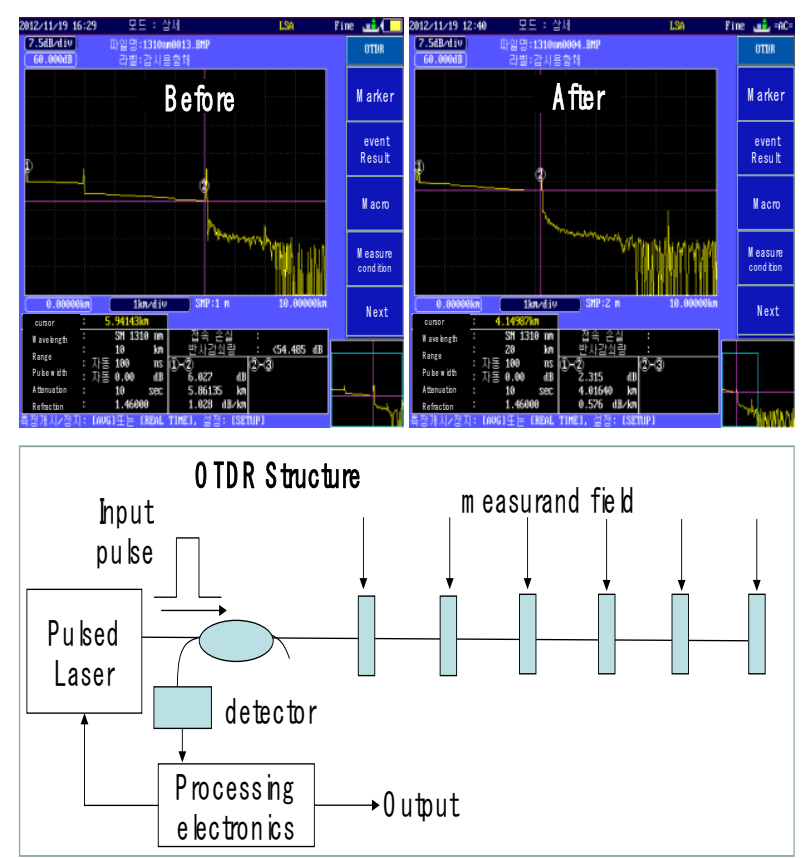

Fig. 6. Pre- and post-event OTDR measurements[6]

The measurement was made by emitting optical pulse signals through the OTDR and sensing the signals coming back from the optical link. Switching was made using a pulsed laser, with the switching time ranging between 10 $\mu \mathrm{s}$ and $1 \mathrm{~ns}$. An OTDR event refers to a point where the scattered light changes or attenuation occurs, which involves, in this case, losses related to cable bending, connection, and fiber cable breakage[6]. The main control processor unit in Fig. 7 plays a role in system monitoring and control. With an in-built Freescale XPC 862 processor, centralized control of alarms and fault management in the shelf and LED display are carried out. With the 100BaseT Ethernet access port provided, data communication was configured through internal IPC, external EMS, and $\mathrm{MMI}^{7}$ ports based on RS-232. The optical line monitoring unit ${ }^{8}$ was configured to monitor 4 channels per unit in real time, checking the delay value, distance (1 time/s), signal attenuation, and optical power input/output loss. To track a line failure, the optical length and access segment were

\footnotetext{
7 MMI (Mixed Mode Communication Interface): a plug-and play support mode with multiple transducers in bus connection. 8 OLMU (Optical Line Management Unit): an optical line remote monitoring system including optical fiber closure opening/closing alarm and periodic measurement of loss changes[6].
}

measured by the OTDR. In order for a unit thus configured to be able to accommodate an eight optical line feeder ring, the SW8U (Optical Switch 1x8 Unit) was extended, so that testing could be performed at switching times of less than $10 \mathrm{~ms}$ and an insertion loss of less than $1 \mathrm{~dB}[6]$.

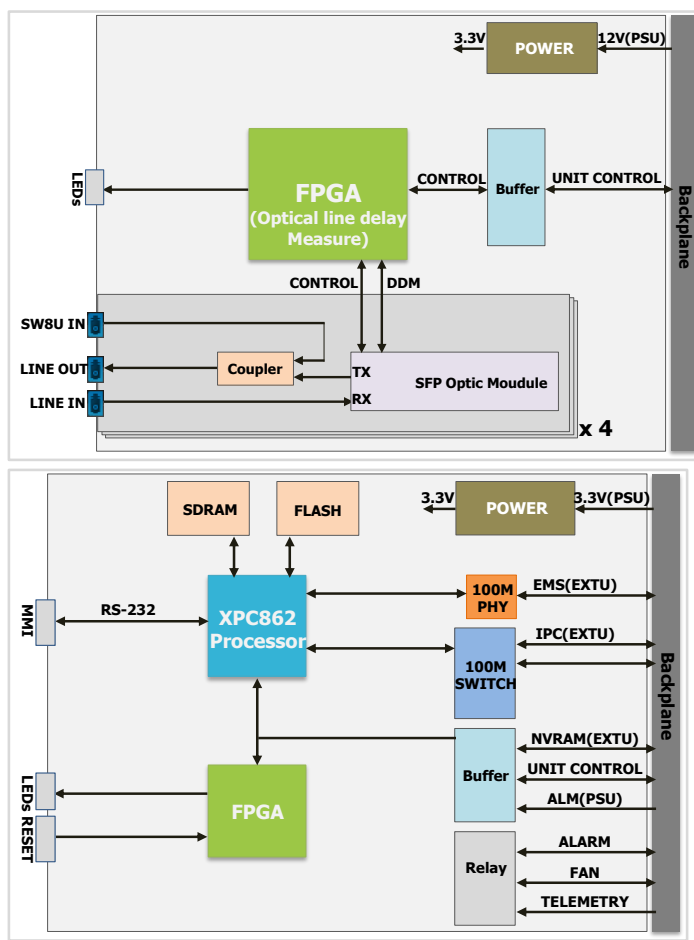

Fig. 7.

Block diagram of the optical line monitoring system[6].

\section{Conclusion}

This paper proposed a system technology capable of centralized remote detection of fiber failure or defects caused during the opening or closing of an optical fiber closure. The performance of the proposed method was tested using an existing Raychem closure. For testing purposes, a prototype implementing the proposed method was fabricated and run in a feeder network at a distance of about $9 \mathrm{~km}$ from the central control system (CCS). As performance outputs, the alarm level and loss diagnosis were evaluated. Currently available optical line remote management systems provide real time signal monitoring through OTDR-based measurement of faulty locations and monitoring and analysis of loss characteristics. The connector loss detected by the existing optical fiber closure monitoring system was $0.1 \mathrm{~dB}$. In this study, it was tested whether fusion or splice loss can be detected within the standard level of $-22 \mathrm{~dB}$, considering $0.03 \mathrm{~dB}$ per $\mathrm{km}$ of optical line. Korean telecom companies are allowed to provide B2B and B2C channels only when they can guarantee maximum optical loss of $-23 \mathrm{~dB}$ on the company-side equipment. Should each telecom company configure a monitoring closure, each company would need to install

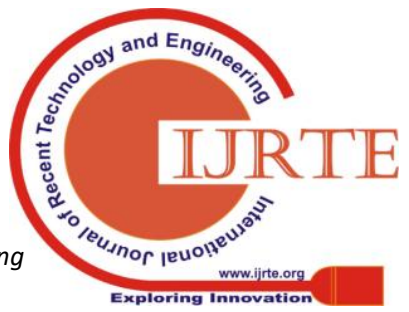




\section{OPTICAL LINE MONITORING SYSTEM USING OPTICAL FIBER CLOSURE}

optical dark fiber and connectors in a large number of splice closures, which may entail length restrictions due to losses. However, since the new system proposed in this study is applied in city areas rather than in backhaul networks, there are no problems caused by optical loss. Moreover, the proposed optical fiber closure surveillance system is very simple, allowing anybody to easily handle it. Thus differentiating itself from other methods, it has a high potential for garnering market share. Also, it is costeffective owing to its advantages of performing monitoring by attaching devices such as connectors, sliding guides, and stoppers on the closure cover, irrespective of its volume and size, without deforming the closure itself. It enables constant real-time monitoring by a small team, thus reducing maintenance costs. This is all the more significant in light of the current situation of constantly expanding area covered by optical lines and subsequent increases in maintenance and repair needs and the number of facilities and systems such as NMS, GIS systems, among others, currently existing in communication companies. In the future, it is expected that research will be carried out until the miniaturization of the equipment can be achieved because the wavelength is different from the actual core, instead of the dark fiber, and integrated control is developed in the central control router or switch. Furthermore, the optical line remote management system can play an important role as a platform linking any existing systems currently run by telecom companies, such as NMS and GIS. Future research will have to focus on developing a monolith-type device and miniaturization so that it can be applied to the central control system router or switch using varying wavelengths of the active fiber instead of dark fiber.

\section{ACKNOWLEDGMENT}

This paper was prepared by the SK Broadband Consortium as part of the "2019 10Giga Internet Promotion business Project," which is a joint project of the Ministry of Science and ICT and the National Information Society Agency (NIA).

\section{REFERENCE}

[1] K. W. O, D. H. Hyun, B. S. Lee, K. Y. Gwak, and H. Y. Choi, "A study on development of optical fiber monitoring system using optical coupler," in Proc. KICS Summer Conf., pp. 713-716, Jeju Island, Korea, July 2006.

[2] E. S. Jang, K. S. Park, S. I. Kim, S. H. Choi, and B.W. Lee, "A study on effective maintenance and operation system of fiber optic lines," J. Inst. Electron. Eng. Korea, vol. 21, no. 1, pp. 54-57, July 1998.

[3] KT "A study on development of optical fiber operation management system," Korea Telecom Research, Dec. 1996.

[4] ROZE Inc., "Optical cable connection divergence box and optical cable monitoring system," Patent application no. 10-2012-0049932, May 2012.
[5] D.Y. Jeon, S.H. Seok, and B.-D. Jung, "A study on monitoring system of the optical cable failure with OTDR and GIS technology," in Proc. KICS Fall Conf., pp. 189-191, Seoul, Korea, Nov. 2008.

[6] W. S. Chae, "Optical fiber control management system technical specification," SKTelecom Network Inst. Broadband Tech. Lab., ver. 1.1, pp. 5-25, Nov 2012.

[7] Sunil Inc., "A study on enterprise for international exchanges and cooperation : a study market trends enterprise of optical fiber closures," Korea Assoc. Photonics Ind. Develop., pp. 1-106, June 2001.

[8] Telecordia Technologies "Generic requirement for remote fiber testing systems (RFMSs)," TA-NWT001295 issue2, Jan. 2000.

[9] Bellcore "TSC/RTO and OTAU generic requirement for remote optical fiber testing," issue1, June 1995.

[10] ITU-T, "Transmission characteristics of optical components and subsystems," ITU-T Recommendation G.671, Apr. 2002.

[11] ITU-T, "Spectral grids for WDM application : CWDM frequency grid," ITU-T Recommendation G.694.2, Feb. 2004.

[12] ITU-T, "Optical Interface for coares wavelength division multiplexing application," ITU-T Recommendation G.695, Apr. 2004.

[13] ITU-T, "Optical fiber cable maintenance criteria for access networks," ITU-T Recommendation L.53, May 2003.

[14] ROZE Inc., "Optical cable connection divergence box and optical cable monitoring system," Patent application no. 10-2012-0062320, June 2012.

[15] ITU-T, "Optical fiber cable maintenance criteria for in service fiber testing in the access networks," ITUT Recommendation L.66, May 2007.

[16] ITU-T, "Characteristics of a single-mode optical fiber and cable," ITU-T Recommendation G.652, Aug. 2001.

[17] SKbroadband, "The basic curriculum of fiber line operation," SKB Operations Support Team, pp.77-83, July 2012

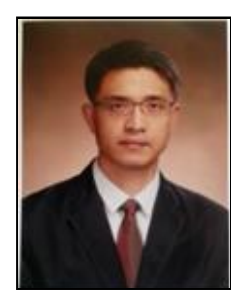

First A. Author So-Ki Jung.

I was born in Korea and Feb. 14, 1971 I graduated from Seoul School of Integrated Sciences \& Technologies (aSSIST) in February 2015 with Ph.D. Management of Technology.

Major field of study : commercialization of technology, sensor network,

Optical communication engineering,

Work experience : I'm currenty working in SKbroadband as R\&D module leader for 3years. I have been working in IT field broadband business for 20years. I work engineers to developer product and service. I have been publishing article in the passing 8ysears, the article are about smart phone monitoring system, 4pair $2.5 \mathrm{G}$ solution, optical return filter, voice of customer, SDN/NFV etc.
Blue Eyes Intelligence Engineering

\& Sciences Publication 